\title{
Cerebral air embolism in a neonate following cardiopulmonary resuscitation
}

\author{
Feico Jan Halbertsma • Peter Andriessen
}

Received: 28 May 2008 /Revised: 11 September 2008 / Accepted: 17 September 2008 / Published online: 25 October 2008

(C) Springer-Verlag 2008

A preterm infant with a history of infant respiratory distress syndrome requiring surfactant administration and mechanical ventilation experienced sudden cardiac arrest 5 days after extubation. Cardiopulmonary resuscitation (CPR) was started, but without success. Head CT revealed extensive intracranial and extracranial intravascular air (Fig. 1), confirmed at post-mortem examination. The cardiac arrest was attributed to an occluding thrombus in the inferior vena cava.

Two conditions must be present for air embolism to occur: direct communication between a source of air and the vasculature, and a pressure gradient. The clinical course, post-mortem findings and analysis of the infusion chart excluded gas-producing infection, necrotizing enterocolitis and iatrogenic air infusion as likely causes of the airembolism. We postulate that the site of air entry was the lung and the pressure gradient needed for air embolism to occur was related to CPR.

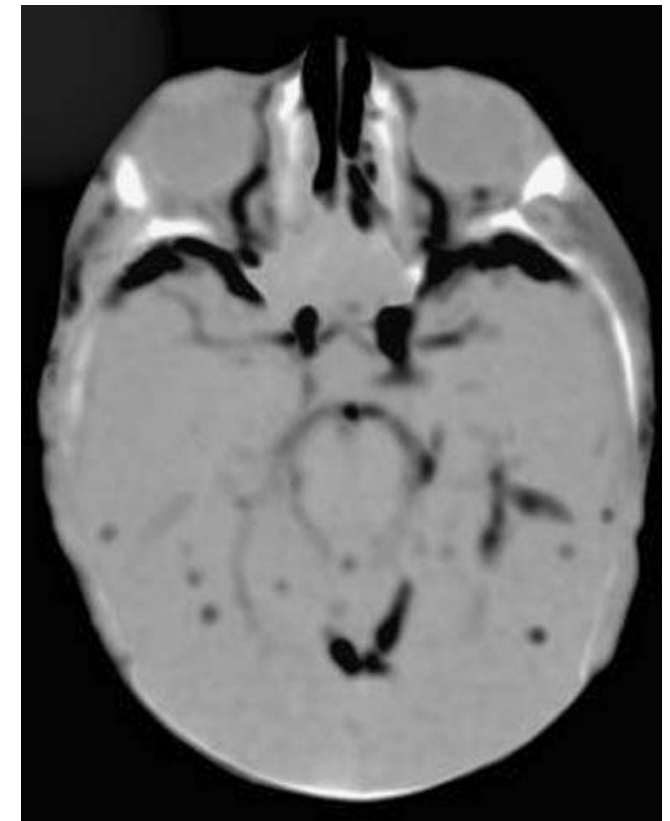

Fig. 1 Head CT 